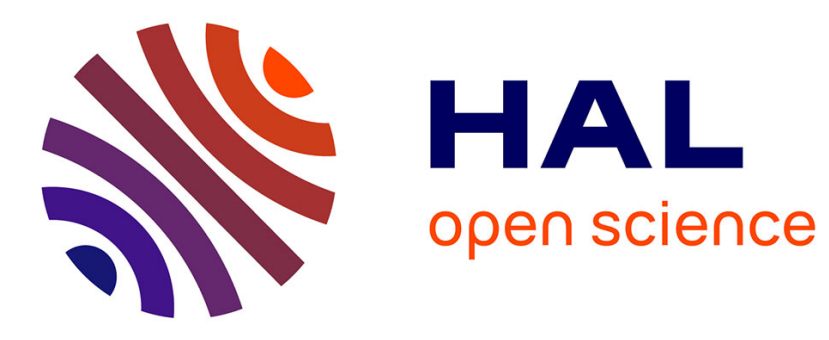

\title{
The Potential of Telemedicine
}

Bibiana Metelmann, Camilla Metelmann, Konrad Meissner, Michael Wendt, Joao Goncalves, Peadar Gilligan, Ahjoku Amadi-Obi, Donal Morris, Eleni Patouni, Martin von Der Heyden

\section{- To cite this version:}

Bibiana Metelmann, Camilla Metelmann, Konrad Meissner, Michael Wendt, Joao Goncalves, et al.. The Potential of Telemedicine. 10th IFIP International Conference on Artificial Intelligence Applications and Innovations (AIAI), Sep 2014, Rhodes, Greece. pp.30-37, 10.1007/978-3-662-44722-2_4. hal-01391026

\section{HAL Id: hal-01391026 \\ https://hal.inria.fr/hal-01391026}

Submitted on 2 Nov 2016

HAL is a multi-disciplinary open access archive for the deposit and dissemination of scientific research documents, whether they are published or not. The documents may come from teaching and research institutions in France or abroad, or from public or private research centers.
L'archive ouverte pluridisciplinaire HAL, est destinée au dépôt et à la diffusion de documents scientifiques de niveau recherche, publiés ou non, émanant des établissements d'enseignement et de recherche français ou étrangers, des laboratoires publics ou privés. 


\title{
The Potential of Telemedicine
}

\author{
Bibiana Metelmann ${ }^{1,2^{*}}$, Camilla Metelmann ${ }^{2 *}$, Konrad Meissner ${ }^{2}$, \\ Michael Wendt ${ }^{2}$, Joao Goncalves ${ }^{3}$, Peadar Gilligan ${ }^{4}$, Ahjoku Amadi- \\ $\mathrm{Obi}^{4}$, Donal Morris ${ }^{5}$, Eleni Patouni ${ }^{6}$, and Martin von der Heyden ${ }^{2}$ \\ ${ }^{1}$ Klinik und Poliklinik für Anästhesiologie und Intensivmedizin, \\ Universitätsmedizin Greifswald, Fleischmannstraße 42-44, 17475 Greifswald, \\ Germany, bibiana.metelmann@uni-greifswald.de \\ ${ }^{2}$ Klinik und Poliklinik für Anästhesiologie und Intensivmedizin, \\ Universitätsmedizin Greifswald, Greifswald, Germany \\ ${ }^{3}$ One Source, Consultoria Informatica Lda., Coimbra, Portugal \\ ${ }^{4}$ The Royal College of Surgeons in Ireland, Dublin, Ireland \\ ${ }^{5}$ RedZinc Services Ltd., Dublin, Ireland \\ ${ }^{6}$ National and Kapodistrian University of Athens, Athens, Greece \\ ${ }^{*}$ B. Metelmann and C. Metelmann contributed equally to this work
}

\begin{abstract}
Telemedicine as a communication technology to overcome geographical distances can increase the quality of medicine. The prerequisite for telemedicine is that two persons or groups of persons are connected with each other. Often this connection is built beforehand during a face-to-face-meeting when both partners apportion the communication devices. If an emergency patient is not already part of a telemedicine project, the connection has to be newly created and the device to build the connection has to be brought to the patient. In the EU-funded LiveCity-Project the hypothesis was evaluated, that in emergency situations a telemedicine connection between a patient and a remote medical doctor can be accomplished by a device brought to the patient by paramedics. It was to be established if communication with a head mounted video-camera coupled with a LTE internet connection was feasible for this purpose.
\end{abstract}

Keywords: Telemedicine, emergency medicine, head mounted video-camera, simulation, LiveCity

\section{Introduction}

Telemedicine represents communication and information technologies that, when together, can help diagnose and treat diseases of patients over a geographical distance $[1,2]$. The word "telemedicine", which is a hybrid word containing the Greek "tele" and Latin "medicus", was first used by Kenneth Thomas Bird in the 1970s and is often translated as "medicine at a distance" $[3,4]$. Albeit there are more than 100 
different peer-reviewed definitions of the word "telemedicine", there is no single agreed definition.[5] Telemedicine is an important future topic, which is for example highlighted on a national scale in the coalition agreement of the new German Government[6] and on a global scope by the World Health Organization, which established a Global Observatory for eHealth[2].

There are two dimensions of communication in telemedicine. One is a horizontal communication between two or more medical experts (e.g. medical doctors in different hospitals) and the other is a vertical communication between a medical expert and a patient (e.g. medical doctor and patient at home). The vertical dimension is also between two healthcare-providers with different levels of medical expertise (e.g. emergency doctor and paramedic). Based on that, there is the possibility to have a medical supervisor for both medical staff and medical non-experts. There are several situations in which such help from a distance might be useful, e.g. a nurse in a family practice helping a patient at home with his daily treatment of chronic diseases. One goal of telemedicine is to reduce hospital admissions and to provide care to a patient in his familiar surroundings.[7] Another goal is to treat urgent worsening of chronic diseases or emergencies. [8, 9]

The German medical emergency system consists of two partners: the paramedics and the emergency doctor[10]. While the paramedics respond to every emergencycall, the emergency doctor is only alerted in certain situations. Criteria to alert an emergency doctor are severe damage of the body or danger to life.[10] The evaluation of severity of every emergency case is done based on the information established during the emergency call and according to determined regulations.[11] The paramedics and the emergency doctor are then alerted independently.

In $49,5 \%$ of all emergency cases an emergency doctor is alerted, too. [12] In the last decade there was an increased need for an emergency doctor detectable. [12] In 99,1\% the paramedics and emergency doctors meet via the rendezvous system. [12] This means that the paramedics and the emergency doctor reach the emergency site with different vehicles independently to start working together at the emergency site[12, 13]. The concept of the rendezvous system was established, because there are more paramedics than emergency doctors. Therefore it is possible to maintain additional ambulance stations with paramedics.[12]. In average the paramedics in Germany arrive after 8.7 minutes while the emergency doctor reaches the emergency site after 12.3 minutes[12]. Thus in most cases in the German medical emergency system, the paramedics reach the patient earlier than the emergency doctor.

The prerequisite for telemedicine is that two persons or groups of persons are connected with each other by the means of a communication technology. Often this connection is built beforehand during a face-to-face-meeting when both partners apportion the communication devices. When using telemedicine in emergency medicine, there is no possibility to meet beforehand and establish a connection. If an 
emergency patient is not already part of a telemedicine project, the connection has to be newly created and the devices to build the connection have to be brought to the patient.

\section{Research Context}

In the EU-funded LiveCity-Project this hypothesis was evaluated, where in emergency situations a telemedicine connection between the patient and a remote medical doctor can be accomplished by the means of a device brought to the patient by paramedics. LiveCity, short term for "Live Video-to-Video Supporting Interactive City Infrastructure", studies how live video connections via LTE can improve the quality of life of European Citizens in various situations.

The Greifswald subgroup studied the use of this LTE video connection in simulated medical emergency situations. As shown above in most cases the paramedics reach the patient earlier than the emergency doctor does. Therefore there is a certain period of time, in which the paramedics are without guidance of an emergency doctor. In addition there are other situations in which the paramedics at the emergency site are without an emergency doctor although one is required. As explained above the emergency dispatcher team makes an initial assessment of the situation based on the alert-call. Depending on this initial assessment, the decision is made, whether to alert an emergency doctor or not. There are some cases, in which the need for an emergency doctor is not apparent from the beginning, so that the emergency doctor isn't alerted.

The LiveCity-Project examines these situations - paramedics being without the help of an emergency doctor at the emergency site. If the paramedics want to consult a medical doctor, they could do that via telemedicine.

There is for instance the possibility to connect via a live-video so that the medical doctor can see the patient and his vital signs as done in the LiveCity-Project. Based on that, he is able to help with diagnostics and treatment, therefore minimizing the time it takes to start the right treatment. Starting the right treatment as early as possible is one of the main goals of emergency medicine, e.g. when treating myocardial infarction, stroke or trauma [14-16].

In 2002, the European Resuscitation Council (ERC) established during a conference held in Florence, Italy, the term "First Hour Quintet"[17-19]. This concept states five life threatening diseases, in which fast medical treatment is crucial for medical outcome concerning morbidity and mortality. Examples are stroke, myocardial infarction and traffic accidents, which are among the leading causes of death in Europe[20, 21]. To improve the therapy of stroke the American Heart Association and American Stroke Association gave recommendations to implement the use of telemedicine in emergency treatment of stroke in 2009.[22] 


\section{Methodology}

In the LiveCity-Project the telemedicine-connection between the patient experiencing an emergency and the emergency doctor stationed at a hospital was to be established with a video-camera with a LTE Internet connection. In this project the remote emergency doctor is called "Tele Emergency Doctor". The video-camera, which was especially developed for this purpose, was brought to the patient by the paramedics. One paramedic wears the camera with a headband, enabling the Tele Emergency Doctor to see the same things the paramedic is seeing. Therefore the paramedic was able to show to the Tele Emergency Doctor the patient, his vital signs and all other important information while having both hands free to work. Moreover the Tele Emergency Doctor was thus able to help the paramedic with diagnosing and treating the emergency. For ethical reasons the study was not done with patients but was simulated in realistic and praxis-oriented scenarios in a simulation center.

The study was designed as a randomized, two-armed crossover study trial. 2 paramedics treated together as a team 5 "patients" without the Tele Emergency Doctor (control cases) and 5 "patients" with help of the Tele Emergency Doctor (experimental cases).

The paramedics approached 10 different scenarios, which were especially developed for this study. Those 10 scenarios were matched pairs belonging to one of the five categories: stroke, myocardial infarction, traffic accidents, pregnancy and rare diseases. While the first three categories were chosen, because they are part of the First Hour Quintet (see above), the last two were created due to the fact that they are a special challenge for the paramedics and emergency doctors and require exceptional expertise. Every scenario was independently evaluated by 3 paramedics and 3 medical doctors regarding practicability.

To minimize influences of confounders, there was a special randomization regarding the chronological order of scenarios. Each scenario was equally tested as a control case and experimental case. Every first group started with the control cases and every second group with the experimental cases.

For all scenarios the mannequin called Laerdal Resusci Anne was used. In every scenario it was initially placed either on a sofa or on the floor, depending on the emergency simulated, but the paramedics were able to move it around as needed.

During the study the paramedics and emergency doctors were asked to fill out specially developed questionnaires. The questions covered different topics, including medical, technical, practical and psychological aspects. 


\section{Results}

10 emergency doctors and 21 paramedics aged between 18 and 50 years were recruited. More than 350 questionnaires were completed.

The paramedics were asked, whether they would prefer in their daily work to have more help with practical, manual skills (e.g. endotracheal intubation) or with finding the right diagnosis and establishing the right therapy. More than two-thirds answered, they encounter more often situations, in which they need theoretical rather than practical support (Fig. 1).

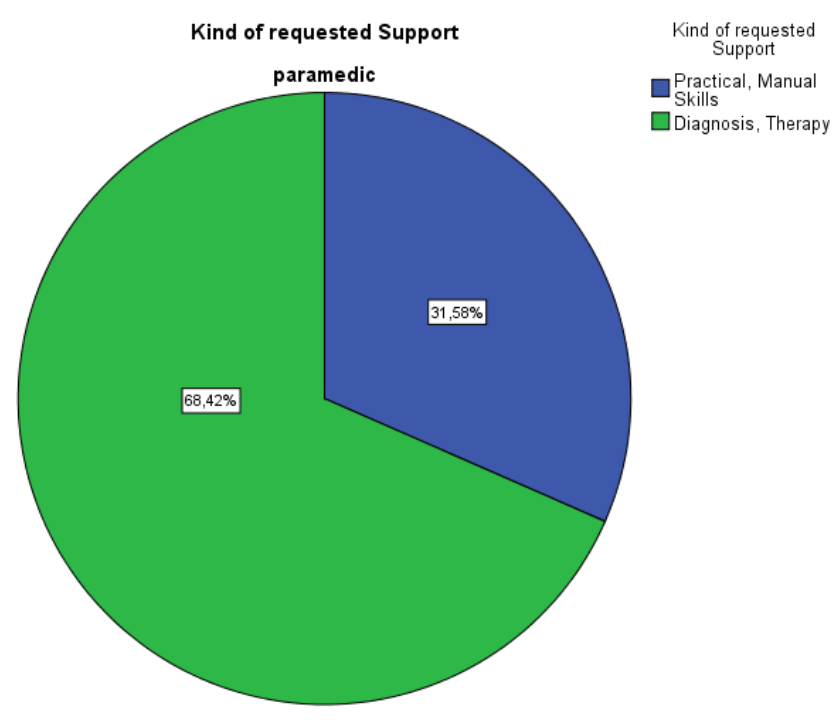

Fig. 1 Kind of requested Support

Furthermore roughly two-thirds stated that they would call the Tele Emergency Doctor in cases, where they normally wouldn't call an emergency doctor (Fig.2). 


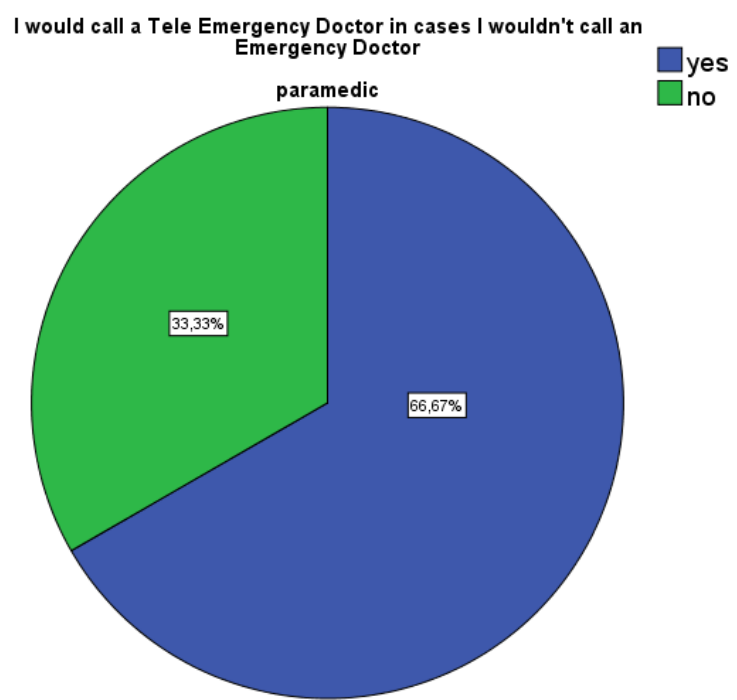

Fig. 2 I would call a Tele Emergency Doctor in cases I wouldn’t call an Emergency Doctor

After finishing all the simulations, the paramedics were asked to rate the assertion "I considered the Tele Emergency Doctor as helpful." 71\% answered "agree", 29\% "partly agree" and no one "partly disagree" or "disagree" (Fig. 3).

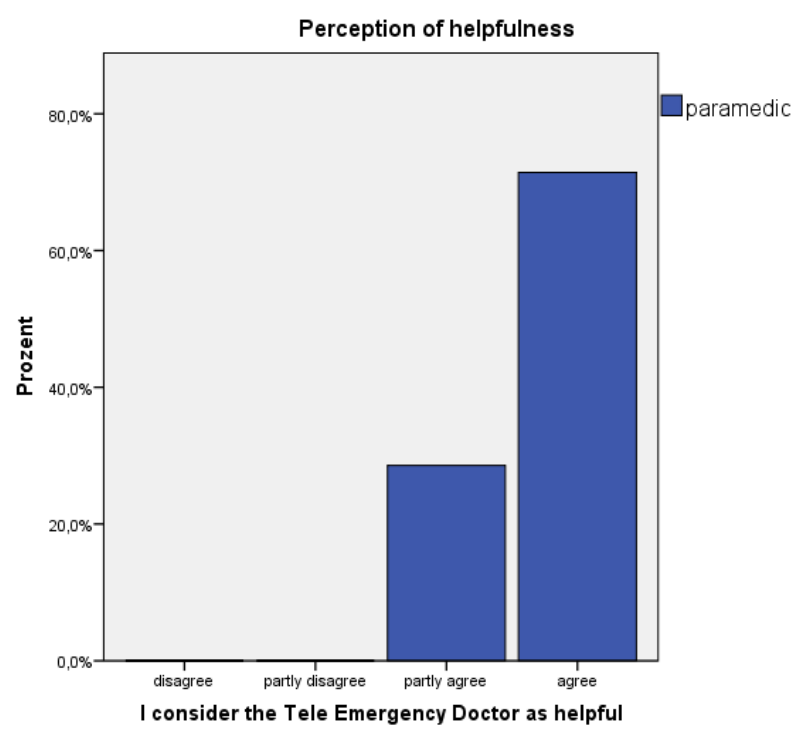

Fig. 3 Perception of helpfulness 
As shown by Fig. 4 paramedics and emergency doctor think the Tele Emergency Doctor could lead to a faster start of treatment.

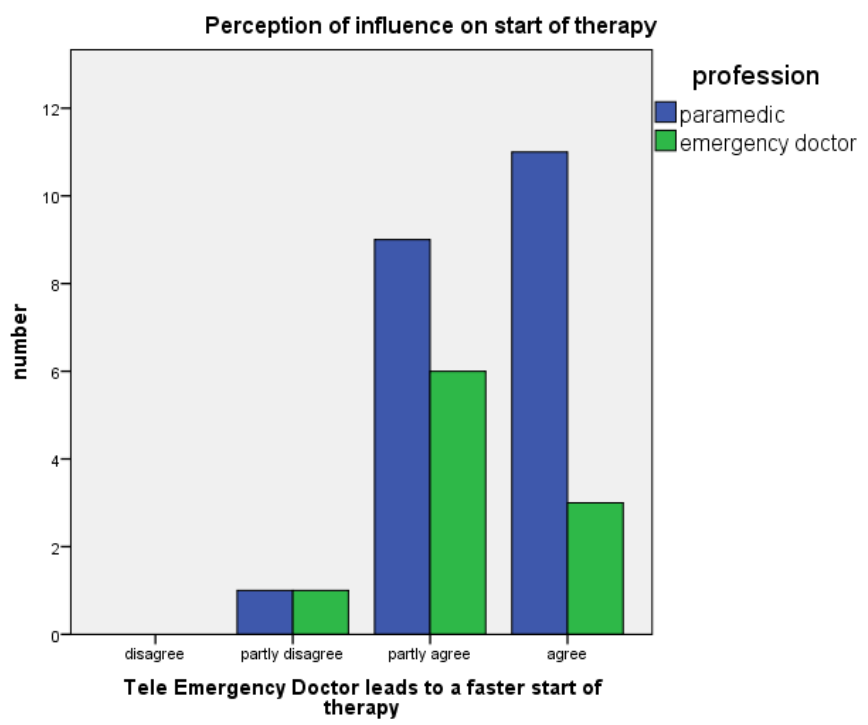

Fig. 4 Perception of influence on start of therapy

A communication between the paramedics and the Tele Emergency Doctor via the head-mounted camera was realizable and audio/picture quality was good enough so that the Tele Emergency Doctor could help with the diagnostics and treatment.

\section{Conclusions}

This study analyzed the use of telemedicine with a head-mounted video camera in emergency medicine. Paramedics, who were alone at the emergency site, got assistance of a Tele Emergency Doctor, who was watching the video in another room on a laptop and could communicate with the paramedics via the camera.

The paramedics stated, that they encounter more often situation in which they need theoretical help than practical help. This theoretical support can be given not only by an emergency doctor at the emergency site, but also by a Tele Emergency Doctor via a camera. As shown by Figure 1-3 a Tele Emergency Doctor would be helpful. Furthermore participants got the feeling that a Tele Emergency Doctor could decrease the time it takes to start the right treatment. As explained above, time is a very crucial point in emergency medicine. An earlier start of treatment can lead to a significant decrease in morbidity and mortality and save life. 
One limitation of this study is the relatively small number of participants.

It could be shown, that a communication with this headmounted camera with LTE Internet connection is feasible. Hence it can be concluded, that a videoconnection between paramedics at the emergency site and a Tele Emergency Doctor is practical and that it could potentially be accomplished with help of LiveCity technology.

The authors of this study would further like to conclude, that a Tele Emergency Doctor might be a very good addition to the existing German medical emergency system. Further studies are on the way.

Acknowledgments: The present article has been structured in the context of the LiveCity ("Live Video-to-Video Supporting Interactive City Infrastructure") European Research Project and has been supported by the Commission of the European Communities - DG CONNECT (FP7-ICT-PSP, Grant Agreement No.297291).

\section{References}

1. Glossarbegriff Telemedizin, B.f. Gesundheit, Editor 24.01.2014: http://www.bmg.bund.de/glossarbegriffe.

2. Telemedicine - Opportunities and developments in Member States: report on the second global survey on eHealth 2009, in Global Observatory for eHealth series Volume 22011, World Health Oragnization.

3. Strehle, E.M. and N. Shabde, One hundred years of telemedicine: does this new technology have a place in paediatrics? Archives of Disease in Childhood, 2006. 91(12): p. 956-959.

4. Benger, J., A review of telemedicine in accident and emergency: the story so far. J Accid Emerg Med, 2000(17): p. 157-164.

5. Sood, S., et al., What is telemedicine? A collection of 104 peer-reviewed perspectives and theoretical underpinnings. Telemed J E Health, 2007. 13(5): p. 573-90.

6. Deutschlands Zukunft gestalten; Koalitionsvertrag zwischen CDU, CSU und SPD; 18. Legislaturperiode, C.-L. CDU Deutschlands, SPD, Editor Dezember 2013: Union Betriebs-GmbH. p. 99-100.

7. Koch, B., et al., Regional Health Care (RHC). Notfall + Rettungsmedizin, 2009. 12(6): p. 461-466.

8. Shah, M.N., et al., High-intensity telemedicine-enhanced acute care for older adults: an innovative healthcare delivery model. J Am Geriatr Soc, 2013. 61(11): p. 2000-7.

9. Saleh, S., et al., Re-admissions to hospital and patient satisfaction among patients with chronic obstructive pulmonary disease after telemedicine video consultation - a retrospective pilot study. Multidiscip Respir Med, 2014. 9(1): p. 6.

10. Harding, U., et al., „Schlaganfall immer mit Notarzt?“ - „Pro“. Medizinische Klinik Intensivmedizin und Notfallmedizin, 2013. 108(5): p. 408-411.

11. Schilling, M., et al., Zuweisungskonzept bei akutem Schlaganfall. Der Nervenarzt, 2012. 83(6): p. 759-765. 
12. Reinhard Schmiedel, H.B., Leistungen des Rettungsdienstes 2008/09, B.f. Straßenwesen, Editor 2011: Dr. Schmiedel GmbH, Bonn.

13. Wahlperiode, D.B., Bericht über Maßnahmen auf dem Gebiet der Unfallverhütung im Straßenverkehr 2008 und 2009 (Unfallverhütungsbericht Straßenverkehr 2008/2009), B.u.S. Bundesministerium für Verkehr, Editor 2010.

14. Members, A.T.F., et al., ESC Guidelines for the management of acute myocardial infarction in patients presenting with ST-segment elevation: The Task Force on the management of ST-segment elevation acute myocardial infarction of the European Society of Cardiology (ESC). European Heart Journal, 2012.

15. Lyden, P., Thrombolytic Therapy for Acute Stroke - Not a Moment to Lose. New England Journal of Medicine, 2008. 359(13): p. 1393-1395.

16. Sharma, A. and P. Jindal, Principles of diagnosis and management of traumatic pneumothorax. J Emerg Trauma Shock, 2008. 1(1): p. 34-41.

17. Krafft, T., et al., European Emergency Data Project EMS Data-based Health Surveillance System Project Report.

18. Nilsen, J.E., Improving quality of care in the Emergency Medical Communication Centres (EMCC) in Konferanse for medisinsk nødmeldetjeneste 7. - 8.nov. 20122012: Sola, Norway.

19. Lackner, C.K., et al., Von der Rettungskette zum akutmedizinischen Netzwerk. Notfall + Rettungsmedizin, 2009. 12(1): p. 25-31.

20. Fischer, M., Factors influencing outcome after prehospital emergencies - a european perspective, in EUROANESTHESIA 20072007: München, Deutschland.

21. Fischer, M., Emergency medical services systems and out-of-hospital cardiac arrest Cardiac Arrest. 2007: Cambridge University Press.

22. Schwamm, L.H., et al., A review of the evidence for the use of telemedicine within stroke systems of care: a scientific statement from the American Heart Association/American Stroke Association. Stroke, 2009. 40(7): p. 2616-34. 